\title{
PENGARUH SUPERVISORY BEHAVIOR, BUDAYA ORGANISASI DAN MOTIVASI
}

\author{
Mariana, Aryana Satrya, Wilfridus B.Elu \\ Universitas Terbuka (UT) Jakarta, Indonesia \\ Email: yanamariana.siput115@gmail.com, aryana@ui.ac.id,wilfriduse@yahoo.com
}

\begin{abstract}
Each organization has a goal that it wants to achieve, namely the survival of the organization. Human resources are one of the most important production factors, without which their organization will have difficulty in achieving the goal. Thisresearch was organized to analyze and find out the factors that influence turnover intention in my school. This study uses sampling techniques where all 119 teachers are used as samples and data obtained from questionnaires are processed using Structural Equation Model (SEM) analysis techniques using Partial Least Square (PLS). The results of the analysis show that all hypotheses are accepted. There is a positive and significant influence of supervisory behavior, organizational culture and motivation on job satisfaction. There is a negative and significant influence of supervision behavior, organizational culture, motivation and job satisfaction on turnover intention. In the results of the indirect influence test found supervision behavior, organizational culture and motivation have an influence on turnover intention through mediation of job satisfaction. With demikian the tenth hypothesis is accepted. The results of this study show that in order to reduce turnover rates, management should pay attention to the job satisfaction of teachers in schools or employees at companies and thevariables that affectthem.
\end{abstract}

Keywords: supervisory behavior; organizational culture; motivation; job satisfaction; turnover intention; school

\section{Abstrak}

Setiap organisasi memiliki tujuan yang ingin dicapainya, yaitu kelangsungan hidup dari organisasi tersebut. Sumber daya manusia merupakan salah satu faktor produksi yang terpenting, tanpa mereka organisasi akan mengalami kesulitan dalam mencapai tujuan. Penelitian ini bertujuan untuk menganalisis dan mengetahui faktor-faktor yang memengaruhi turnover intention di sekolahku. Penelitian ini menggunakan metode penelitian kuantitatif dengan pendekatan kausal. Teknik sampling dimana seluruh guru yang berjumlah 119 digunakan sebagai sampel dan data yang diperoleh dari kuesioner diolah menggunakan teknik analisis Structural Equation Model (SEM) dengan menggunakan Partial Least Square (PLS). Hasil analisis menunjukan bahwa semua hipotesis diterima. Terdapat pengaruh positif dan signifikan perilaku supervisi (supervisory behavior), budaya organisasi dan motivasi terhadap kepuasan kerja. Terdapat pengaruh negatif dan signifikan perilaku supervisi, budaya organisasi, motivasi dan kepuasan kerja terhadap turnover intention. Dalam hasil uji pengaruh tidak langsung didapati perilaku supervisi, budaya organisasi dan motivasi memiliki pengaruh terhadap turnover intention melalui mediasi kepuasan kerja. Dengan demikian kesepuluh hipotesis

$\begin{array}{ll}\text { How to cite: } & \text { Mariana, Aryana Satrya dan Wilfridus B. Elu (2021) Pengaruh Supervisory Behavior, Budaya } \\ & \text { Organisasi Dan Motivasi (3)6. https://doi.org/10.36418/syntax-idea.v3i6.1230 } \\ \text { E-ISSN: } & \text { 2684-883X } \\ \text { Published by: } & \text { Ridwan Institute }\end{array}$


diterima. Hasil penelitian ini menunjukan bahwa untuk mengurangi tingkat turnover, manajemen harus memperhatikan kepuasan kerja guru di sekolah atau karyawan pada perusahaan dan variabel-variabel yang memengaruhinya.

Kata Kunci: perilaku supervisi; budaya organisasi; motivasi; turnover intention; kepuasan kerja; sekolah

\section{Pendahuluan}

Setiap organisasi memiliki tujuan yang ingin dicapainya, yaitu kelangsungan hidup dari organisasi tersebut. Sumber daya manusia merupakan salah satu faktor produksi yang terpenting, tanpa mereka organisasi akan mengalami kesulitan dalam mencapai tujuan. Karyawan dalam hal ini merupakan sumber daya manusia yang berperan besar dalam menentukan maju mundurnya suatu organisasi, sehingga organisasi membutuhkan karyawan yang berkualitas, terampil dan dapat diandalkan agar organisasi dapat melangsungkan kehidupannya. Dengan demikian organisasi perlu mempertahankan karyawan yang berkualitas, terampil dan dapat diandalkan tersebut agar mereka tidak mempunyai keinginan untuk pindah ke organisasi atau perusahaan lain (Hussain, Saeed, Ibrahim, \& Iqbal, 2018).

Karyawan yang meninggalkan organisasi kemudian digantikan oleh karyawan baru dan berlangsung terus menerus merupakan masalah serius dalam bidang sumber daya manusia (Yin-Fah, Foon, Chee-Leong, \& Osman, 2010). Karyawan, terlebih yang sudah terampil dan dapat diandalkan sangat menentukan baik atau tidaknya denyut nadi kehidupan organisasi. Bila bagian yang sangat penting tersebut meninggalkan organisasi, secara otomatis kehidupan organisasi akan terganggu dan bila tidak diatasi akan menimbulkan masalah. Faktor yang paling menonjol yang memengaruhi karyawan untuk meninggalkan organisasi adalah keinginan untuk mendapatkan pekerjaan atau karir yang lebih baik atau karena merasa tidak puas terhadap beberapa aspek dari pekerjaan mengajar mereka (Ingersoll \& May, 2012).

Organisasi atau perusahaan-perusahaan yang sukses, baik yang bergerak dalam bidang layanan jasa ataupun barang, mempunyai strategi untuk menjaga karyawan yang berkualitas agar tetap bertahan dalam perusahaan. Strategi tersebut misalnya dengan memberikan upah yang bagus, lingkungan kerja yang atraktif dan system bagi hasil atau bonus. Melalui upah yang bagus perusahaan dapat menjaring karyawan yang berkualitas. Lingkungan kerja yang atraktif membuat karyawan tidak merasa bosan dan pemberian bonus membuat karyawan merasa hasil kerja mereka dihargai. Karyawan akan tetap bekerja di suatu perusahaan, bila perusahaan melalui manajernya memperlihatkan ketertarikan dan perhatian kepada karyawan, karyawan tahu apa yang diharapkan dari mereka, diberi tugas yang sesuai dengan kemampuan mereka dan menerima pengakuan serta timbal balik yang positif maka mereka (karyawan tersebut) akan tetap bekerja pada perusahaan tersebut (Maaitah, 2018).

Sekolah merupakan organisasi yang bergerak dalam bidang layanan jasa, sehingga memerlukan karyawan untuk bergabung dan berkarya secara bersama-sama dalam mencapai tujuan organisasi dan tujuan individu. Karyawan yang bergabung tersebut menjadi tenaga pendidik atau guru yang bertanggung jawab memberikan layanan 
pendidikan yang berkualitas. Layanan pendidikan yang berkualitas dapat tercapai bila karyawan tersebut mempunyai keterampilan dan dapat diandalkan. Untuk mencapai hal tersebut banyak organisasi tidak ragu untuk memberikan berbagai pelatihan sesuai dengan keterampilan yang saat ini diperlukan oleh guru demi tercapainya layanan pendidikan yang berkualitas. Sekolah juga berusaha menghadirkan lingkungan kerja yang atraktif, memberikan tugas yang sesuai dengan kemampuan guru serta memberikan apresiasi serta timbal balik yang positif agar guru tidak meninggalkan sekolah. Namun, itu semua nampaknya belum cukup untuk membuat guru tetap bekerja pada sekolah. Sekolah juga mengalami masalah dengan tingkat perputaran karyawan (turnover intention) seperti organisasi-organisasi lainya.

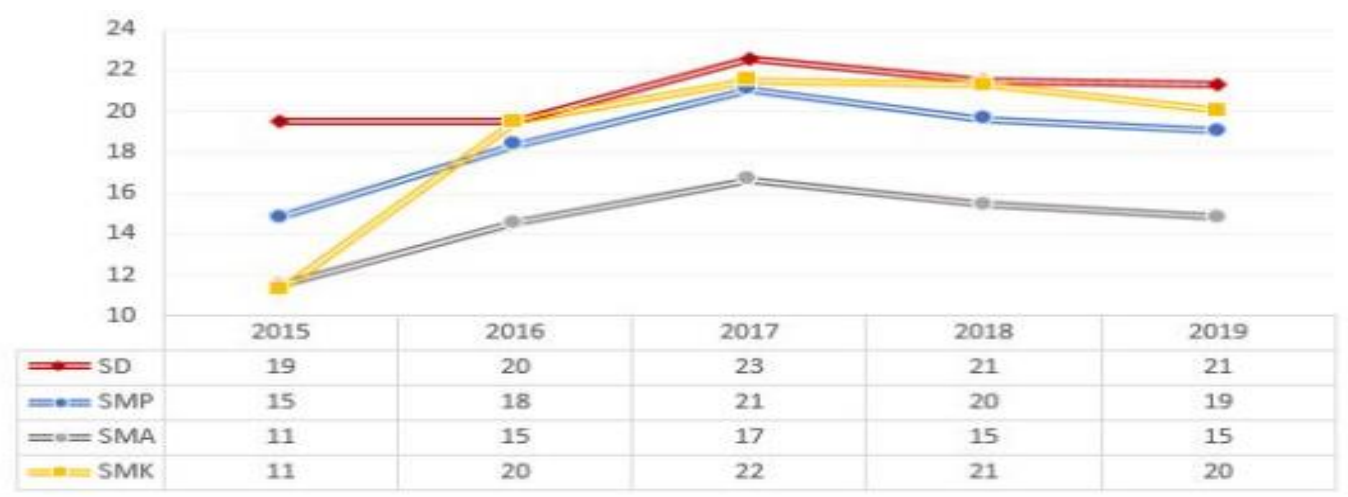

Gambar 1

Rasio Guru dan Murid di DKI Jakarta, 2015-2019

Sumber: Dinas Pendidikan DKI Jakarta (Akbar, 2019)

Keterbatasan jumlah guru terjadi di Provinsi DKI Jakarta. Kepala Dinas Pendidikan DKI Jakarta, Sopan Ardianto, memperkirakan akan terjadi kekurangan tenaga pengajar pada 2022 karena sekitar 2.500 guru di DKI Jakarta pensiun setiap tahunnya (Putsanra, 2017). Berdasarkan gambar 1 (satu) menunjukkan adanya peningkatan rasio jumlah guru terhadap jumlah siswa di DKI Jakarta. Sebagai contoh, rasio guru dan murid SD pada tahun 2015 adalah 1:19, berarti setiap 1 (satu) guru SD di DKI Jakarta memiliki beban mengajar 19 murid secara rata-rata. Namun pada tahun 2019 rasio tersebut mengalami peningkatan menjadi 1:21, sehingga menunjukkan adanya peningkatan beban kerja guru SD. Peningkatan rasio ini pada umumnya juga terjadi pada jenjang pendidikan lainnya (Akbar, 2019).

Terbatasnya rasio guru dan murid di DKI Jakarta diperparah dengan masalah perputaran karyawan (turnover intention). Berdasarkan laporan hasil penelitian yang penulis peroleh, (Sarwesti \& Zein, 2019) dan (Suryani, 2014) menjelaskan bahwa Yayasan Perguruan Al-Fattah Medan dan Yayasan PGRI Cabang Cipayung juga mengalami masalah dengan turnover intention guru. Turnover intention guru pada Yayasan Perguruan Al-Fattah Medan sebesar 7.03\% pertahun antara tahun 2010 sampai 2014 (Sarwesti \& Zein, 2019). Rata-rata turnover intention guru Yayasan PGRI Cabang Cipayung dari tahun 2004-2013 sebesar 3,4\%. Terdapat tiga sekolah di bawah naungan 
Yayasan PGRI Cabang Cipayung, yaitu SMP PGRI 9, SMA PGRI 4, dan SMK PGRI 16 Cipayung (Suryani, 2014).

Tabel 1

Tingkat Turnover Guru

\begin{tabular}{lcccccc}
\hline \multirow{1}{*}{ Divisi } & \multicolumn{2}{c}{$\mathbf{2 0 1 6 / 2 0 1 7}$} & \multicolumn{2}{c}{$\mathbf{2 0 1 7 / 2 0 1 8}$} & \multicolumn{2}{c}{$\mathbf{2 0 1 8 / 2 0 1 9}$} \\
\cline { 2 - 7 } & Jumlah & Guru & Jumlah & Guru & Jumlah & Guru \\
& Guru & Keluar & Guru & Keluar & Guru & Keluar \\
\hline TK & 30 & 4 & 30 & - & 30 & 1 \\
SD & 45 & 12 & 48 & 8 & 46 & 9 \\
SMP, SMA/SMK & 46 & 14 & 52 & 10 & 52 & 12 \\
\hline Jumlah & 121 & 30 & 130 & 18 & 128 & 22 \\
\hline Persentase & & 25 & & 15 & & 19 \\
\hline
\end{tabular}

Sekolahku yang terletak di Jakarta juga mengalami masalah dengan turnover intention guru seperti Yayasan Perguruan Al-Fattah Medan dan Yayasan PGRI Cabang Cipayung. Data pada Tabel 1 yang peneliti peroleh dari Human Resource Department (HRD) Sekolahku menjelaskan tingkat turnover intention guru di sekolah ini. Meskipun tingkat turnover guru menunjukkan kecenderungan semakin menurun, namun masih lebih dari 10\%. Bahkan pada tahun 2018/2019 kembali meningkat menjadi 19\%. Sedangkan tingkat turnover guru yang ditentukan oleh pihak sekolah adalah sebesar 10\%. Jadi dapat disimpulkan bahwa permasalahan turnover guru di Sekolahku cukup tinggi. Tingkat turnover intention yang tinggi ini menarik perhatian peneliti.

Guru yang keluar dari SekolahKu tidak hanya menimbulkan masalah bagi manajemen, namun juga bagi guru yang masih bertahan di sekolah. Guru yang keluar memengaruhi motivasi, hasil kerja serta kerja sama tim guru yang masih bertahan bekerja di sekolah (Bosomtwe, T. E., \& Obeng, 2018), (Achoui \& Mansour, 2007). Bagi guru yang masih bertahan, kehilangan rekan kerja yang sudah lama bekerja bersama-sama meninggalkan perasaan yang tidak nyaman. Pada bulan-bulan awal kepergian rekan kerja, mereka akan tetap teringat bagaimana kesan selama bekerja sama dengan rekan kerja yang telah mengundurkan diri.

Saat ini, pergantian karyawan adalah mimpi buruk di banyak organisasi (Lee, Chen, Wang, \& Dadura, 2010). Ketika seorang karyawan pindah, organisasi tersebut lebih dari sekedar dipengaruhi oleh biaya merekrut dan melatih pendatang baru; organisasi juga kehilangan kontinuitas kerja dan produktivitas, serta menderita karena kepercayaan dan reputasi organisasi yang buruk (Koh \& Goh, 1995), (Balsam, Gifford, \& Kim, 2007). Dapat disimpulkan bahwa pergantian karyawan dapat menjadi tantangan serius bagi organisasi, terutama, ketika karyawan yang berkinerja tinggi meninggalkan organisasi dan seringkali sulit untuk menggantinya (Idiegbeyan-Ose, Opeke, \& Nwokeoma, 2018).

Jika karyawan puas dengan pekerjaannya dan mengalami emosi positif selama bekerja mereka melakukan pekerjaan mereka dengan lebih baik dan memilih tetap bersama organisasi untuk periode waktu yang lebih lama (Colquitt, J.A., LePine, J.A., and Michael, 2011). Ketidakpuasan adalah kunci karyawan meninggalkan organisasi dan banyak alasan karyawan puas atau tidak puas berada dalam kontrol pemimpin (Hughes, R. L., Ginnett, R.C., \& Curphy, 2012). Hal yang sangat penting yang dapat 
dilakukan oleh manajer untuk meningkatkan kepuasan kerja karyawan adalah fokus pada bagian intrinsik pekerjaan itu sendiri, seperti membuat pekerjaan menantang dan menarik (Robbins \& Judge, 2013).

Adanya perilaku supervisi yang memperhatikan kepentingan karyawan akan berakibat pada kegairahan kerja, semangat dalam bekerja, merasa nyaman dan aman dan keadaan ini akan menciptakan kepuasan kerja bagi para karyawan dan sekaligus dapat menurunkan tingkat turnover intention. Hal ini sesuai dengan penelitian yang dilakukan oleh (Mathieu, Fabi, Lacoursiere, \& Raymond, 2016), (Mahmood, Ali, Khadim, \& Amina, 2015), (Adebayo \& Ogunsina, 2011) yang menunjukkan bahwa supervisory behavior berpengaruh terhadap kepuasan kerja dan turnover intention.

Upaya meningkatkan kepuasan kerja guru dapat dilakukan oleh manajemen sekolah melalui budaya organisasi yang menekankan kerja sama tim dan loyalitas sambil mendorong inovasi dan kewirausahaan (Lund, 2003). Pemberdayaan dan kerja tim merupakan bagian penting dalam budaya organisasi. Hal ini disebabkan karena dengan adanya tim dalam organisasi berarti mereka didorong untuk merancang aktivitas pekerjaan mereka sendiri. Ide-ide yang mereka sampaikan kepada manajemen akan dipertimbangkan dan diikuti oleh umpan balik. Pencapaian pekerjaan melalui tim ini menambah kepuasan pekerjaan karyawan (Usman, 2019). Dengan demikian budaya organisasi mempunyai dampak positif terhadap kepuasan kerja dan dapat menurunkan niat karyawan untuk keluar (Usman, 2019), (Bosomtwe, T. E., \& Obeng, 2018).

Disamping perilaku supervisi dan budaya organisasi, kepuasan kerja guru juga dapat dicapai melalui motivasi. Kepuasan kerja dapat tercapai bila guru termotivasi untuk bekerja berdasarkan kemauannya sendiri. Kepuasan kerja membuat guru lebih mempertimbangkan dan memerhatikan organisasi (Saleem, Mahmood, \& Mahmood, 2010). Mengutip pendapat (Saleem et al., 2010), pelatihan merupakan proses pengembangan secara sistematis terhadap perilaku, keterampilan dan pengetahuan guru agar tercipta motivasi yang mengarah pada kepuasan kerja mereka. Untuk membuat guru tetap termotivasi, manajemen dapat menerapkan berbagai metode untuk membuat guru tetap termotivasi dan mempertahankan sumber daya manusia yang terampil. Dengan demikian kepuasan guru akan tercipta dan akan memberikan yang terbaik dari diri mereka (Hussain et al., 2018). Hasil penelitian dari para peneliti tersebut menjelaskan bahwa untuk mempertahan guru dapat dilakukan dengan menjaga guru agar tetap termotivasi sehingga kepuasan kerja guru dapat tercapai.

Penelitian ini dilakukan di suatu sekolah swasta dengan jumlah sampel terbesar adalah guru perempuan dan sebagian besar responden adalah guru yang sudah menikah. Penelitian ini bertujuan menganalisa pengaruh variabel bebas perilaku supervisi, budaya organisasi, motivasi dan kepuasan kerja terhadap variabel terikat turnover intention. Selain menganalisa pengaruh langsung variabel bebas terhadap variabel terikat, penelitian ini juga menganalisa pengaruh tidak langsung perilaku supervisi, budaya organisasi dan motivasi terhadap turnover intention melalui mediasi kepuasan kerja.

Setelah mempelajari hasil penelitian para peneliti terdahulu, maka untuk menciptakan kepuasan yang tinggi bagi guru serta menurunkan tingkat turnover intention di Sekolahku dapat dilakukan melalui perilaku supervisi (supervisory 
behavior), budaya organisasi dan motivasi. Turnover intention yang tinggi telah menjadi masalah serius tidak hanya bagi organisasi yang bergerak di bidang pendidikan namun juga bagi organisasi yang bergerak dibidang nonpendidikan. Masalah ini menjadi serius karena organisasi kehilangan sumber daya manusia yang bermutu dengan skill yang sangat dibutuhkan oleh organisasi untuk dapat bertahan dalam persaingan yang semakin ketat. Organisasi akan semakin merasakan kerugian akibat turnover karyawan apabila telah melakukan berbagai upaya mulai dari menjaring calon karyawan yang berkualitas sampai melakukan berbagai pelatihan untuk memperbaiki skill karyawan sehingga memenuhi kebutuhan organisasi.

Dalam organisasi, supervisi dilaksanankan oleh supervisor atau pengawas. Supervisor atau pengawas merupakan manajer garis depan yang bertanggung jawab kepada manajer tingkat menengah. Pengawas bertugas merencanakan, memotivasi, mengarahkan dan mengontrol pekerjaan karyawan non manajerial. Tanggung jawab pengawas adalah memastikan karyawan bekerja sesuai dengan rencana dan instruksi yang dibuat oleh manajer tingkat atas dan menengah (Page dan Wosket, 2001).

Budaya organisasi adalah suatu sistem makna bersama yang dianut oleh para anggota yang membedakan suatu organisasi dari organisasi-organisasi lainnya (Robbins \& Judge, 2013). Budaya organisasi merupakan perekat bagi semua hal di dalam organisasi. Budaya merupakan perekat sosial yang membantu menyatukan organisasi dengan menyediakan standar bagi anggota tentang apa yang seharusnya dikerjakan dan dikatakan (Robbins \& Judge, 2013).

Menurut (Veithzal, 2005) memberikan penjelasan bahwa seorang individu dalam usaha mendapatkan suatu hal yang menjadi tujuan hidupnya dipengaruhi oleh serangkaian sikap dan nilai-nilai yang tidak dapat dilihat, namun mendorong individu tersebut. Dorongan tersebut terbagi menjadi dua, yaitu arah perilaku (bekerja demi mencapai tujuan) dan kekuatan perilaku (seberapa keras individu dalam berusaha). Motivasi meliputi perasaan unik, pikiran dan pengalaman masa lalu yang merupakan bagian dari hubungan internal dan eksternal perusahaan. Selain itu motivasi dapat pula diartikan sebagai dorongan individu untuk melakukan tindakan karena mereka ingin melakukanya. Apabila individu termotivasi, mereka akan membuat pilihan yang positif untuk melakukan sesuatu, karena dapat memuaskan keinginan mereka.

Berdasarkan latar belakang dan hasil penelitian terdahulu penulis tertarik untuk meneliti kembali faktor-faktor yang mempengaruhi kepuasan kerja dan kinerja karyawan dengan mengajukan judul: "Pengaruh Perilaku Supervisi, Budaya Organisasi, Motivasi terhadap Turnover Intention dengan Kepuasan Kerja sebagai Variabel Mediasi di sekolahku".

\section{Metode Penelitian}

Metode yang digunakan dalam penelitian ini adalah metode penelitian kuantitatif dengan pendekatan kausal. Penelitian ini dimaksudkan untuk membangun suatu gambaran sesungguhnya terhadap suatu fenomena yang berada dalam konteks penelitiannya. Dengan penelitian kuantitatif ini akan dikumpulkan berbagai data dalam rangka pengujian hipotesis atau menjawab pernyataan-pernyatan yang berhubungan 
dengan masalah yang diteliti. Penelitian ini menggunakan teknik sampling dimana seluruh guru yang berjumlah 119 digunakan sebagai sampel dan data yang diperoleh dari kuesioner diolah menggunakan teknik analisis SEM PLS.

\section{Hasil dan Pembahasan}

\section{Analisis Data dan Hasil}

1) Demografi Responden

Sampel pada penelitian ini sebanyak 119 responden pada SekolahKu di Jakarta dengan karakteristik responden disajikan pada Tabel 4.1.

Tabel 1

Karakteristik Responden

\begin{tabular}{llll}
\hline \multirow{2}{*}{ Karakteristik } & \multicolumn{1}{c}{ Kategori } & \multicolumn{2}{c}{ Karyawan } \\
\cline { 3 - 4 } Jenis Kelamin & Laki-laki & 29 & 24,4 \\
& Perempuan & 90 & 75,6 \\
\hline \multirow{2}{*}{ Status } & Jumlah & 119 & 100 \\
\hline & Menikah & 58 & 48,7 \\
& Belum menikah & 61 & 51,3 \\
\hline Usia & Jumlah & 119 & 100 \\
& S.d. 20 tahun & 2 & 1,7 \\
& $>50$ tahun & 7 & 5,9 \\
& 41-50 tahun & 12 & 10,1 \\
& 21-30 tahun & 44 & 37 \\
& 31-40 tahun & 54 & 45,4 \\
\hline Pendidikan & Jumlah & 119 & 100 \\
& S2 & 3 & 2,5 \\
& Diploma & 4 & 3,4 \\
& S1 & 112 & 94,1 \\
\hline Masa Kerja & Jumlah & 119 & 100 \\
& $<1$ tahun & 15 & 12,6 \\
& $11-15$ tahun & 15 & 12,6 \\
& 3 -5 tahun & 20 & 16,8 \\
& $1-2$ tahun & 25 & 21 \\
& 6-10 tahun & 44 & 37 \\
\hline & Jumlah & 119 & 100 \\
\hline & Sumber: Olahan peneliti $(2020)$ & \\
\hline
\end{tabular}

Dari Tabel 1 terlihat bahwa responden yang dominan adalah jenis kelamin perempuan sebesar 75,6 \% dibanding dengan jenis kelamin laki-laki sebesar 24, $4 \%$. Responden berdasarkan status yang paling dominan adalah berstatus belum menikah sebesar 51, 3\% diikuti dengan responden berstatus menikah sebesar $48,7 \%$. Responden berdasarkan usia yang paling dominan adalah umur $31-40$ tahun sebesar 45,4\%. Berdasarkan pendidikan adalah responden dengan pendidikan S1 sebesar 94,1\%. Karakteristik responden berdasarkan masa kerja yang paling dominan adalah masa kerja 6-10 tahun sebesar $37 \%$.

\section{2) Uji Validitas dan Relibilitas Instrumen Penelitian}


Sebelum penelitian dilanjutkan dilakukan uji coba validitas dan reliabilitas instrumen penelitian yang melibatkan 40 responden. Validitas kuesioner dilihat dari nilai factor loading dan dikatakan valid apabila menunjukkan angka > 0,50. Berdasarkan hasil uji analisis faktor KMO dan Bartlett's test untuk variabel perilaku pengawasan di Tabel 4.6 terlihat angka KMO Measure of sampling Adequacy (MSA) pada variabel perilaku pengawasan 0.871. Hal ini menunjukkan kecukupan dari sampel. I

Tabel 2

Validitas Variabel

Perilaku Pengawasan pada Tahap Uji Coba KMO and Bartlett's Test

\begin{tabular}{lrr}
\hline \multicolumn{2}{l}{ Kaiser-Meyer-Olkin Measure of Sampling Adequacy. } & .871 \\
\hline Bartlett's Test of Sphericity & Approx. Chi-Square & 197.382 \\
\cline { 2 - 3 } & df & 28 \\
\cline { 2 - 2 } & Sig. & .000
\end{tabular}

Sumber: Olahan peneliti (2020)

Tabel 2 menunjukkan bahwa delapan (8) item pertanyaan untuk variabel perilaku supervisi semuanya valid, terlihat dari nilai factor loading semua item pertanyaan lebih dari 0,50 .

Tabel 2

Analisis Faktor Perilaku Supervisi

\begin{tabular}{cccc}
\hline No & Item & Factor Loading & Keterangan \\
\hline 1 & PS1 & 0,763 & Valid \\
\hline 2 & PS2 & 0,816 & Valid \\
\hline 3 & PS3 & 0,835 & Valid \\
\hline 4 & PS4 & 0,835 & Valid \\
\hline 5 & PS5 & 0,811 & Valid \\
\hline 6 & PS6 & 0,843 & Valid \\
\hline 7 & PS7 & 0,742 & Valid \\
\hline 8 & PS8 & 0,838 & Valid \\
\hline \multicolumn{5}{c}{ Sumber: Olahan peneliti (2020) } \\
\end{tabular}

Berdasarkan hasil uji analisis faktor KMO dan Bartlett's test untuk variabel budaya organisasi di Tabel 2 terlihat angka KMO Measure of sampling Adequacy (MSA) pada variabel budaya organisasi 0.897. Hal ini menunjukkan kecukupan dari sampel. 
Tabel 3

Validitas Variabel Budaya Organisasi pada Tahap Uji Coba KMO and Bartlett's Test

\begin{tabular}{llr}
\hline Kaiser-Meyer-Olkin Measure of Sampling Adequacy. & .897 \\
\hline Bartlett's Test of Sphericity & Approx. Chi-Square & 128.828 \\
\cline { 2 - 3 } & df & 21 \\
\cline { 2 - 3 } & Sig. & .000 \\
\hline
\end{tabular}

Tabel 3 menunjukkan bahwa tujuh (7) item pertanyaan untuk variabel budaya organisasi valid, terlihat dari nilai factor loading semua item pertanyaan lebih dari 0,50 .

Tabel 4

Analisis Faktor Budaya Organisasi

\begin{tabular}{cccc}
\hline No & Item & Factor Loading & Keterangan \\
\hline 1 & BO1 & 0,820 & Valid \\
\hline 2 & BO2 & 0,810 & Valid \\
\hline 3 & BO3 & 0,795 & Valid \\
\hline 4 & BO4 & 0,802 & Valid \\
\hline 5 & BO5 & 0,709 & Valid \\
\hline 6 & BO6 & 0,791 & Valid \\
\hline 7 & BO7 & 0,742 & Valid
\end{tabular}

Berdasarkan hasil uji analisis faktor KMO dan Bartlett's test untuk variabel motivasi di Tabel 4 terlihat angka KMO Measure of sampling Adequacy (MSA) pada variabel motivasi kerja .879. Hal ini menunjukkan kecukupan dari sampel.

Tabel 5

Validitas Variabel

Motivasi pada Tahap Uji Coba

KMO and Bartlett's Test

\begin{tabular}{llr}
\hline Kaiser-Meyer-Olkin Measure of Sampling Adequacy. & .879 \\
\hline Bartlett's Test of Sphericity & Approx. Chi-Square & 213.528 \\
\cline { 2 - 3 } & & df \\
\cline { 2 - 3 } & Sig. & .000 \\
\hline
\end{tabular}

Data pada Tabel 5 menunjukkan bahwa delapan (8) item pertanyaan untuk variabel motivasi kerja valid, terlihat dari nilai factor loading semua item pertanyaan lebih dari 0,50 . 
Tabel 6

Analisis Faktor Motivasi

\begin{tabular}{cccc}
\hline No & Item & Factor Loading & Keterangan \\
\hline 1 & M1 & 0,855 & Valid \\
\hline 2 & M2 & 0,827 & Valid \\
\hline 3 & M3 & 0,731 & Valid \\
\hline 4 & M4 & 0,859 & Valid \\
\hline 5 & M5 & 0,824 & Valid \\
\hline 6 & M6 & 0,828 & Valid \\
\hline 7 & M7 & 0,790 & Valid \\
\hline 8 & M8 & 0,803 & Valid
\end{tabular}

Hasil uji analisis faktor KMO dan Bartlett's test untuk variabel kepuasan kerja di Tabel 6 menunjukkan angka KMO Measure of sampling Adequacy (MSA) pada kepuasan kerja .869. Hal ini menunjukkan kecukupan dari sampel.

Tabel 7

Validitas Varriabel

Kepuasan Kerja pada Tahap Uji Coba

KMO and Bartlett's Test

\begin{tabular}{llr}
\hline Kaiser-Meyer-Olkin Measure of Sampling Adequacy. & .869 \\
\hline Bartlett's Test of Sphericity & Approx. Chi-Square & 139.249 \\
\cline { 2 - 3 } & & df \\
\cline { 2 - 3 } & Sig. & .000 \\
\hline
\end{tabular}

Data pada Tabel 7 menunjukkan bahwa tujuh (7) item pertanyaan untuk variabel kepuasan kerja valid, terlihat dari nilai factor loading semua item pertanyaan lebih dari 0,50 .

Tabel 8

Tabel Analisis Faktor Kepuasan Kerja

\begin{tabular}{cccc}
\hline No & Item & Factor Loading & Keterangan \\
\hline 1 & KK1 & 0,839 & Valid \\
\hline 2 & KK2 & 0,754 & Valid \\
\hline 3 & KK3 & 0,727 & Valid \\
\hline 4 & KK4 & 0,761 & Valid \\
\hline 5 & KK5 & 0,766 & Valid \\
\hline 6 & KK6 & 0,810 & Valid \\
\hline 7 & KK7 & 0,838 & Valid
\end{tabular}

Sumber: Olahan peneliti (2020)

Selanjutnya hasil uji analisis faktor KMO dan Bartlett's test untuk variabel turnover intention di Tabel 8 menunjukkan angka KMO Measure of sampling Adequacy (MSA) pada turnover intention .500. Hal ini menunjukkan kecukupan dari sampel. 
Tabel 9

Uji Coba Validitas

Variabel Turnover Intention

KMO and Bartlett's Test

\begin{tabular}{llr}
\hline Kaiser-Meyer-Olkin Measure of Sampling Adequacy. & .500 \\
\hline Bartlett's Test of Sphericity & Approx. Chi-Square & 19.300 \\
\cline { 2 - 3 } & df & .000 \\
\cline { 2 - 3 } & Sig. &
\end{tabular}

Sumber: Olahan peneliti (2020)

Data pada Tabel 9 menunjukkan bahwa dua (2) item pertanyaan untuk variabel turnover intention valid, terlihat dari nilai factor loading semua item pertanyaan lebih dari 0,50 .

Tabel 10

Analisis Faktor Turnover Intention

\begin{tabular}{clcc}
\hline No & Item & $\begin{array}{c}\text { Factor } \\
\text { Loading }\end{array}$ & Keterangan \\
\hline 1 & TO1 & 0,904 & Valid \\
\hline 2 & TO2 & 0,904 & Valid \\
\hline & Sumber: Olahan peneliti (2020) &
\end{tabular}

Angka KMO dan Bartlet's test (nilai chi-square) untuk variabel perilaku supervisi 197.382, budaya organisasi 128.828, motivasi kerja 213.528, kepuasan kerja 139.249 dan turnover intention 19.300 dengan nilai signifikansi 0.000, menunjukkan bahwa adanya korelasi antar variabel dan layak untuk proses lebih lanjut.

Dengan melihat nilai factor loading setiap butir pertanyaan dari semua variabel menunjukkan angka > 0,50 maka semua butir pertanyaan kuesioner valid. Hal ini sesuai dengan penjelasan Hair (2010) bahwa bila nilai factor loading berkisar antara 0,30- 0,40 dianggap memenuhi tingkat minimum dalam mengintepretasikan struktur. Nilai factor loading 0,50 atau lebih dinyatakan signifikan (valid) dan nilai factor loading yang melebihi 0,70 menunjukkan gambaran struktur yang baik dari suatu variabel.

Selanjutnya untuk uji reliabilitas instrumen penelitian disajikan pada tabel 11. Berdasarkan hasil perhitungan SPSS diperoleh nilai Alpha Cronbach keseluruhannya lebih besar dari 0,60. Dengan demikian, berarti setiap variabel dinyatakan reliabel. 
Tabel 11

Uji Coba Reliabilitas Instrumen Penelitian

\begin{tabular}{clcc}
\hline No & \multicolumn{1}{c}{ Variabel } & Conbrach's Alpha & Keputusan \\
\hline 1 & Perilaku Supervisi & 0,921 & Reliabel \\
\hline 2 & Budaya Organisasi & 0,893 & Reliabel \\
\hline 3 & Motivasi & 0,927 & Reliabel \\
\hline 4 & Kepuasan Kerja & 0,896 & Reliabel \\
\hline 5 & Turnover Intention & 0,776 & Reliabel \\
\hline
\end{tabular}

Sumber: Hasil perhitungan SPSS

\section{3) Model Partial Least Square (PLS)}

Pada penelitian ini, pengujian hipotesis menggunakan teknik analisis Partial Least Square (PLS) dengan program smartPLS 3.0. Model pengukuran untuk nilai koefisien jalur dan t-value untuk model persamaan, dapat dilihat pada Gambar 1 dan Gambar 2.

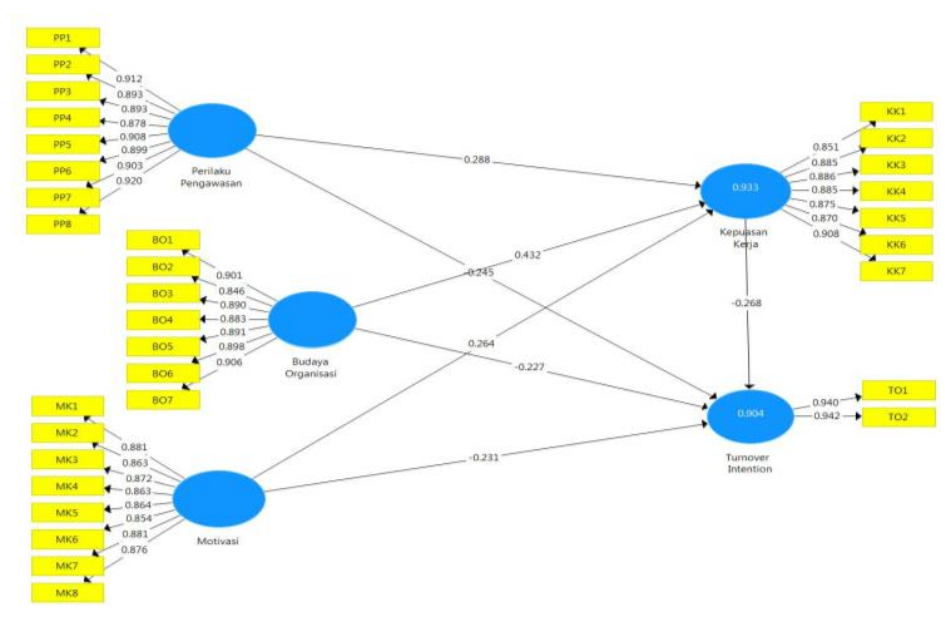

Gambar 1

Outer Model

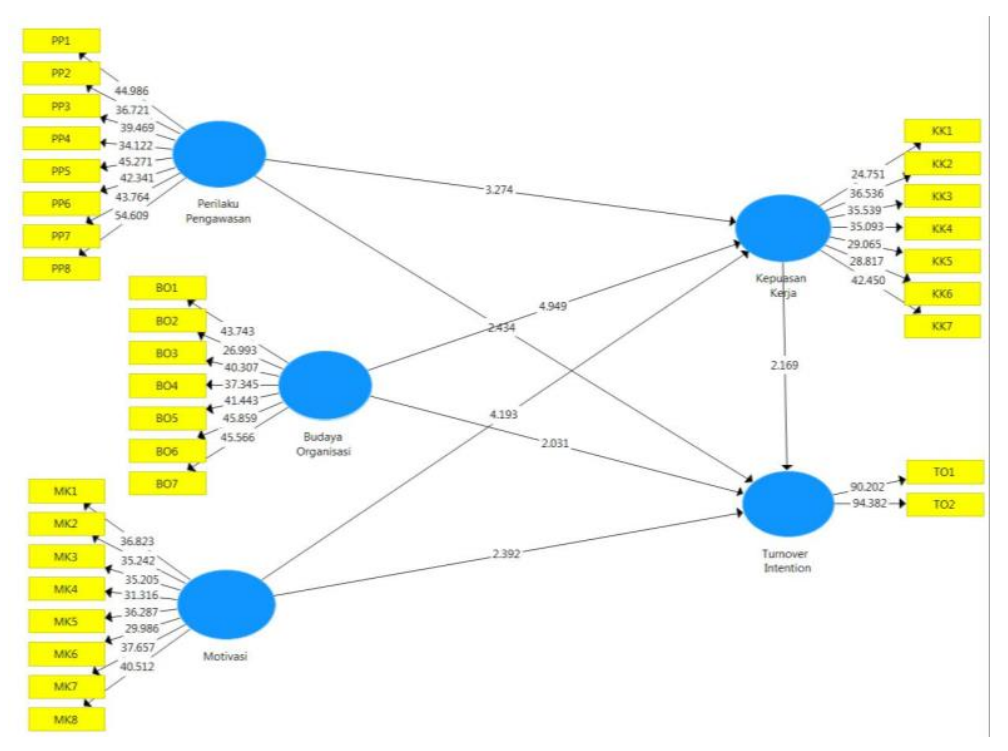

Gambar 2

Inner Model 


\section{4) Evaluasi Outer Model}

\section{a. Convergent Validity}

Untuk menguji convergent validity digunakan nilai outer loading atau loading factor. Suatu indikator dinyatakan memenuhi convergent validity dalam kategori baik apabila nilai outer loading $>0,7$. Berikut adalah nilai outer loading dari masing-masing indikator pada variabel penelitian yang disajikan pada Tabel 12 .

Tabel 12

Outer Loading

\begin{tabular}{|c|c|c|}
\hline Variabel & Indikator & Outer Loading \\
\hline \multirow[t]{8}{*}{ Perilaku Supervisi (X1) } & PS1 & 0,912 \\
\hline & PS2 & 0,893 \\
\hline & PS3 & 0,893 \\
\hline & PS4 & 0,878 \\
\hline & PS5 & 0,908 \\
\hline & PS6 & 0,899 \\
\hline & PS7 & 0,903 \\
\hline & PS8 & 0,920 \\
\hline \multirow[t]{7}{*}{ Budaya Organisasi (X2) } & BO1 & 0,901 \\
\hline & $\mathrm{BO} 2$ & 0,846 \\
\hline & $\mathrm{BO} 3$ & 0,890 \\
\hline & $\mathrm{BO} 4$ & 0,883 \\
\hline & BO5 & 0,891 \\
\hline & BO6 & 0,898 \\
\hline & $\mathrm{BO} 7$ & 0,906 \\
\hline \multirow[t]{8}{*}{ Motivasi (X3) } & M1 & 0,881 \\
\hline & M2 & 0,863 \\
\hline & M3 & 0,872 \\
\hline & M4 & 0,863 \\
\hline & M5 & 0,864 \\
\hline & M6 & 0,854 \\
\hline & M7 & 0,881 \\
\hline & M8 & 0,876 \\
\hline \multirow[t]{7}{*}{ Kepuasan Kerja (Z) } & KK1 & 0,851 \\
\hline & KK2 & 0,885 \\
\hline & KK3 & 0,886 \\
\hline & KK4 & 0,885 \\
\hline & KK5 & 0,875 \\
\hline & KK6 & 0,870 \\
\hline & KK7 & 0,908 \\
\hline \multirow[t]{2}{*}{ Turnover Intention (Y) } & TO1 & 0,940 \\
\hline & TO2 & 0,942 \\
\hline
\end{tabular}

Sumber: Hasil Pengolahan PLS, 2020

Berdasarkan data tabel 12 di atas, diketahui bahwa masing-masing indikator variabel penelitian banyak yang memiliki nilai outer loading > 0,7. Namun, terlihat masih terdapat beberapa indikator yang memiliki nilai outer loading < 0,7. Menurut Chin yang dikutip oleh Imam Ghozali (2014:39), nilai outer loading antara 0,5 - 0,6 sudah dianggap cukup untuk memenuhi syarat convergent validity. Data di atas menunjukkan tidak ada indikator variabel yang nilai outer loading-nya di bawah 0,5 , sehingga 
semua indikator dinyatakan layak atau valid untuk digunakan penelitian dan dapat digunakan untuk analisis lebih lanjut.

\section{b. Discriminant Validity}

Pada bagian ini akan diuraikan hasil uji discriminant validity. Uji discriminant validity dilakukan dengan melihat nilai average variant extracted (AVE) untuk masing-masing indikator dipersyaratkan nilainya harus $>0,5$ untuk model yang baik. Berikut disajikan hasil uji discriminant validity pada Tabel 13.

Tabel 13

Average Variant Extracted (AVE)

\begin{tabular}{|c|c|}
\hline Variabel & AVE \\
\hline Perilaku Supervisi & 0,812 \\
\hline Budaya Organisasi & 0,788 \\
\hline Motivasi & 0,756 \\
\hline Kepuasan Kerja & 0,775 \\
\hline Turnover Intention & 0,886 \\
\hline
\end{tabular}

Berdasarkan tabel 13 di atas, diketahui bahwa nilai AVE variabel perilaku supervisi, budaya organisasi, motivasi, kepuasan kerja dan turnover intention > 0,5. Dengan demikian dapat dinyatakan bahwa setiap variabel telah memiliki discriminant validity yang baik.

\section{c. Composite Reliability}

Composite Reliability merupakan bagian yang digunakan untuk menguji nilai reliabilitas indikator-indikator pada suatu variabel. Suatu variabel dapat dinyatakan memenuhi composite reliability apabila memiliki nilai composite reliability $>0,6$. Tabel 14 adalah nilai composite reliability dari masing-masing variabel penelitian.

Tabel 14

Composite Reliablity

\begin{tabular}{lc}
\hline \multicolumn{1}{c}{ Variabel } & Composite Reliablity \\
\hline Perilaku Supervisi & 0,972 \\
\hline Budaya Organisasi & 0,963 \\
\hline Motivasi & 0,961 \\
\hline Kepuasan Kerja & 0,960 \\
\hline Turnover Intention & 0,939 \\
\hline
\end{tabular}

Sumber: Hasil Pengolahan PLS, 2020

Berdasarkan tabel 14 di atas, dapat diketahui bahwa nilai composite reliability semua variabel penelitian > 0,6. Hasil ini menunjukkan bahwa masing-masing variabel telah memenuhi composite realibility sehingga dapat disimpulkan bahwa keseluruhan variabel memiliki tingkat realibilitas yang tinggi.

\section{d. Cronbach Alpha}

Uji realibilitas dengan composite reability di atas dapat diperkuat dengan menggunakan nilai cronbach alpha. Suatu variabel dapat dinyatakan reliabel atau memenuhi cronbach alpha apabila memiliki nilai cronbach 
alpha $>0,75$. Tabel 15 adalah nilai cronbach alpha dari masing-masing variabel.

Tabel 15

Cronbach Alpha

\begin{tabular}{lc}
\hline \multicolumn{1}{c}{ Variabel } & Cronbach Alpha \\
\hline Perilaku Supervisi & 0,967 \\
\hline Budaya Organisasi & 0,955 \\
\hline Motivasi & 0,954 \\
\hline Kepuasan Kerja & 0,951 \\
\hline Turnover Intention & 0,871 \\
\hline & Sumber: Hasil Pengolahan PLS, 2020
\end{tabular}

Berdasarkan tabel 15 dapat diketahui bahwa nilai cronbach alpha dari masing-masing variabel penelitian > 0,7. Dengan demikian hasil ini menunjukkan bahwa masing-masing variabel penelitian telah memenuhi persyaratan nilai cronbach alpha, sehingga dapat disimpulkan bahwa keseluruhan variabel memiliki tingkat reliabilitas yang tinggi.

\section{Kesimpulan}

Tujuan dari penelitian ini adalah mengetahui faktor-faktor yang memengaruhi turnover intention guru di SekolahKu sehingga manajemen sekolah dapat mempertahankan guru yang berkualitas. Alasan guru meninggalkan sekolah adalah karena ingin mencari pekerjaan yang lebih baik dan mengakibatkan tingkat turnover guru yang tinggi pada tahun 2016-2019. Guru ingin mendapatkan pekerjaan yang lebih menantang dan menarik di luar SekolahKu. Dalam penelitian ini, kepuasan kerja berpengaruh negatif dan signifikan terhadap turnover intention dengan nilai koofiensi sebesar 0,904. Artinya guru yang merasa tidak puas bekerja di SekolahKu sangat besar kemungkinannya untuk meninggalkan sekolah. Kepuasan kerja guru di SekolahKu dipengaruhi oleh perilaku supervisi, budaya organisasi dan motivasi.

Untuk menjaga tingkat intensi turnover guru agar tetap rendah yang menjadi tujuan dari penelitian ini dan tingkat kepuasan guru tetap tinggi, manajemen sekolah harus memperhatikan perilaku supervisi yang dilakukan oleh kepala sekolah. Perilaku supervisi dari kepala sekolah harus lebih memperhatikan kepentingan guru sehingga mereka merasa nyaman. Kepala sekolah dan manajemen harus dapat menciptakan lingkungan sekolah yang kondusif dengan menciptakan budaya organisasi dan memastikan budaya tersebut dilaksanakan dengan baik oleh semua guru dan siswa. Memotivasi dan menjaga tingkat motivasi guru agar tetap tinggi juga hal yang sangat penting dan mempengaruhi tingkat turnover dan kepuasan kerja guru. Hal penting yang harus manajemen lakukan untuk meningkatkan kepuasan kerja guru adalah fokus pada pekerjaan itu sendiri, yaitu dengan merancang dan menjadikan kegiatan belajar mengajar menjadi lebih menantang dan menarik bagi guru.

Bagi peneliti lain diharapkan dapat menambahkan beberapa variabel yang dapat mempengaruhi kepuasan kerja dan turnover intention serta memperluas obyek penelitian agar diperoleh hasil yang lebih maksimal, misalnya gaya kepemimpinan, 
rekan kerja, kompensasi, karir, promosi, komunikasi, stres kerja, dan komitmen organisasi.

\section{BIBLIOGRAFI}

Achoui, Mustapha, \& Mansour, Mourad. (2007). Employee turnover and retention strategies: Evidence from Saudi companies. International Review of Business Research Papers, 3(3), 1-16.Google Scholar

Adebayo, Sulaiman Olanrewaju, \& Ogunsina, S. O. (2011). Influence of supervisory behaviour and job stress on job satisfaction and turnover intention of police personnel in Ekiti State. Journal of Management and Strategy, 2(3), 13. Google Scholar

Akbar, A. (2019). Rasio guru dan murid di DKI Jakarta. Diakses dari https://statistik.jakarta.go.id/rasio-guru-dan-murid-di-dki-jakarta-2019/.

Alam, Shahi Md Tanvir. (2012). Factors affecting job satisfaction, motivation and turnover rate of medical promotion officer (MPO) in pharmaceutical industry: A study based in Khulna city. Asian Business Review, 1(2), 126-131. Google Scholar

Arifin, H. Muhammad. (2015). The Influence of Competence, Motivation, and Organisational Culture to High School Teacher Job Satisfaction and Performance. International Education Studies, 8(1), 38-45. Google Scholar

Balsam, Steven, Gifford, Richard, \& Kim, Sungsoo. (2007). The effect of stock option grants on voluntary employee turnover. Review of Accounting and Finance. Google Scholar

Bosomtwe, T. E., \& Obeng, B. (2018). The link between organizational culture and turnover intention among employees in Ghana. International Journal of Contemporary Research and Review, 9(8), 20951-20958.

Colquitt, J.A., LePine, J.A., and Michael, J. W. (2011). Organizational Behavior. New York: McGraw-Hill.

Hughes, R. L., Ginnett, R.C., \& Curphy, G. (2012). Leadership: Enhancing the Lessons of Experience (7th ed). Singapore: Mc Graw Hill. Google Scholar

Hussain, Jafar, Saeed, M. Zahid, Ibrahim, Muhammad, \& Iqbal, Muzaffar. (2018). Impact of Motivation on Employee Performance and Turnover in Pakistani Educational Institutes. Journal of Education and Practice, 9(16), 87-95. Google Scholar

Idiegbeyan-Ose, Jerome, Opeke, Roseline, \& Nwokeoma, Nwanne M. (2018). Influence of organisational culture on turnover intention of library staff in private university libraries, South-West Nigeria. Academy of Strategic Management Journal, 17(4). Google Scholar 
Ingersoll, Richard M., \& May, Henry. (2012). The magnitude, destinations, and determinants of mathematics and science teacher turnover. Educational Evaluation and Policy Analysis, 34(4), 435-464. Google Scholar

Koh, Hian Chye, \& Goh, Chye Tee. (1995). An analysis of the factors affecting the turnover intention of non-managerial clerical staff: A Singapore study. International Journal of Human Resource Management, 6(1), 103-125. Google Scholar

Lee, Tzong-Ru, Chen, Shiou-Yu, Wang, Saint-Hei, \& Dadura, Agnieszka. (2010). The relationship between spiritual management and determinants of turnover intention. European Business Review. Google Scholar

Lund, Daulatram B. (2003). Organizational culture and job satisfaction. Journal of Business \& Industrial Marketing. Google Scholar

Maaitah, Ayman Mahmoud. (2018). The role of leadership style on turnover intention. International Review of Management and Marketing, 8(5), 24. Google Scholar

MacIntosh, Eric W., \& Doherty, Alison. (2010). The influence of organizational culture on job satisfaction and intention to leave. Sport Management Review, 13(2), 106117. Google Scholar

Mahmood, Faisal, Ali, Nazakat, Khadim, Irfan, \& Amina, Tayyaba. (2015). Relationship of Salary Income, Supervisor Behavior \& Work Load with Employee Turnover: Empirical Study in Private Educational Sector of Paksitan. International Journal of Research, 57. Google Scholar

Mathieu, Cynthia, Fabi, Bruno, Lacoursiere, Richard, \& Raymond, Louis. (2016). The role of supervisory behavior, job satisfaction and organizational commitment on employee turnover. Journal of Management and Organization, 22(1), 113. Google Scholar

Mukhtar, Iskandar, \& Iskandar, I. (2009). Orientasi Baru Supervisi Pendidikan. Jakarta: Gaung Persada. Google Scholar

Niguse, Girma Taye. (2019). The effects of organizational culture on turnover intention: The mediating role of job satisfaction, a case of Oromia Forest and Wild Life Enterprise. African Journal of Business Management, 13(2), 82-89. Google Scholar

Putsanra, D.(2017). Jakarta Diprediksi Kekurangan Guru pada 2022. Diakses dari. Retrieved from https://tirto.id/jakarta-diprediksi-kekurangan-guru-pada-2022cvBv.

Robbins, Stephen P., \& Judge, Timothy A. (2013). Organizational Behavior Edition 15 New Jersey. Pearson Education. Google Scholar

Rosalina, Reinelda Rani, Matin, Matin, \& Kamaludin, Kamaludin. (2018). Pengaruh Kepercayaan dan Kepuasan Kerja terhadap Intensi Turnover Guru SMKS Cikarang 
Utara. SAP (Susunan Artikel Pendidikan), 2(3). Google Scholar

Saleem, Rizwan, Mahmood, Azeem, \& Mahmood, Asif. (2010). Effect of work motivation on job satisfaction in mobile telecommunication service organizations of Pakistan. International Journal of Business and Management, 5(11), 213. Google Scholar

Sarwesti, Ika Desni, \& Zein, Zahari. (2019). Analisis Kebijakan Peningkatan Penghasilan Guru dalam Upaya Menurunkan Turnover di Yayasan Perguruan AlFattah Medan. Al-Irsyad: Jurnal Pendidikan Dan Konseling, 6(1). Google Scholar

Sathyanarayan, Dr K., \& Lavanya, Dr B. Latha. (2018). Effect of Organizational Commitment, Motivation, Attitude towards Work on Job Satisfaction, Job Performance and Turnover Intention\|-VUCA Perspective. Journal of Management, 5(4). Google Scholar

Schermerhorn, John R., Hunt, James G., Osborn, Richard N., \& Uhl-Bien, Mary. (2006). Organizational behaviour. Langara College. Google Scholar

Suryani, Ayu. (2014). Pengaruh kepuasan kerja terhadap intensi turnover pada guru di Yayasan PGRI Cipayung Jakarta Timur. Universitas Negeri Jakarta. Google Scholar

Thatcher, Jason Bennett, Liu, Yongmei, Stepina, Lee P., Goodman, Joseph M., \& Treadway, Darren C. (2006). IT worker turnover: An empirical examination of intrinsic motivation. ACM SIGMIS Database: The Database for Advances in Information Systems, 37(2-3), 133-146. Google Scholar

Tsui, Ming Sum. (2004). Supervision models in social work: From nature to culture. Asian Journal of Counselling, 11(1-2), 7-55. Google Scholar

Usman, Khalid. (2019). Impact of organizational culture, organizational communication and supervisor support on the job satisfaction of employees working in online IT based distance learning institutions of Pakistan. Open Praxis, 11(2), 143-156. Google Scholar

Veithzal, Rivai. (2005). Manajemen Sumber Daya Manusia untuk Perusahaan, edisi kedua, cetakan pertama. Raja Grafindo Persada, Jakarta. Google Scholar 
Mariana, Aryana Satrya,Wilfridus Elu

Yin-Fah, Benjamin Chan, Foon, Yeoh Sok, Chee-Leong, Lim, \& Osman, Syuhaily. (2010). An exploratory study on turnover intention among private sector employees. International Journal of Business and Management, 5(8), 57. Google Scholar

Copyright holder :

Mariana, Aryana Satrya dan Wilfridus B. Elu (2021)

First publication right :

Journal Syntax Idea

This article is licensed under:

(c) $\bigoplus_{\mathrm{BY}} \ominus$ 